\title{
LA JURISPRUDENCIA DEL TRIBUNAL SUPERIOR DE JUSTICIA DE GALICIA COMO ELEMENTO DE DESARROLLO DEL DERECHO CIVIL GALLEGO (SERVIDUMBRES Y SERVENTÍAS) ${ }^{1}$
}

\author{
Ramón P. Rodríguez Montero
}

\begin{abstract}
Sumario: 1. Notas en torno al marco histórico del denominado Derecho privado gallego. 2. La Ley 4/1995, de 24 de mayo, de Dereito civil de Galicia. 3.La importante función desarrollada por el Tribunal Superior de Justicia de Galicia a través de su actividad jurisprudencial. Dos ejemplos de determinación jurisprudencial del derecho en materia de servidumbres y serventias.
\end{abstract}

\section{NOTAS EN TORNO AL MARCO HISTÓRICO DEL DENOMINADO DERECHO PRIVADO GALLEGO.}

El análisis, la explicación y comprensión del fenómeno jurídico en una época antigua en Galicia implica la necesidad de tomar en consideración una serie de factores de tipo económico, social y político que, al hilo del proceso histórico desenvuelto en la formación de la nacionalidad española, se dieron en esta tierra, condicionando su propia experiencia jurídica².

Lejos de las tierras de reconquista, donde se forjaron reinos y esferas de poder y de vida jurídica, Galicia no tuvo entidad política suficiente para poder hacer arraigar, como otros territorios peninsulares con mayor protagonismo político, un sistema de Derecho propio en la Edad Media ${ }^{3}$. En dicha época, salvo las manifestaciones del régimen señorial y municipal -como esferas claramente diferenciadas en las que se reparte el orden jurídico medieval-, que se dieron en Galicia como en los demás territorios de España durante el período de la Reconquista cristiana ${ }^{4}$, no se puede decir que en el territorio gallego -polí-

1 Comunicación presentada al VI Congreso Internacional de Estudios Galegos, organizada por la Asociación internacional de Estudios Galegos, celebrado en La Habana (Cuba) los dias 77 a 21 de abril de 2000.

2 FUENTESECA DIAZ, en Prólogo a la monografía de PAZ ARES, Instituciones al servicio de la Casa en el Derecho Civil de Galicia, 1964, p.9. Cfr., además, para una descripción de las particularidades del fenómeno jurídico en Galicia, desde un planteamiento histórico de conjunto, con amplias referencias bibliográficas, RODRIGUEZ ENNES, Aproximación a la Historia jurídica de Galicia, 1999.

3 FUENTESECA DIAZ, Prólogo a la obra de PAZ ARES, cit., p.7. En opinión de OTERO VARELA, Sobre la Compilación del Derecho foral Gallego, en AHDE XXXV, 1965, p.553 ss., el Derecho foral es cl resultado de un proceso histórico concreto, que encuentra su orígen en época postgótica, y que no parece habelse dado en Galicia. Cfr. RODRIGUEZ ENNES, Aproximación a la Historia jurúdica de Galicia cit., p.35 ss.

4 Según GIBERT, El Derecho Civil de Galicia, en Revista "Nuestro tiempo", núm. 113, 1963, p.538 s., "Bajo el señorío eclesiástico, del arzobispo de Compostela, cuyos titulares recibieron de los reyes atribuciones condales, de las otras Iglesias y de los Monasterios, se desarrolló un régimen de sujección señorial que tiene por base el foro agrario"; asimismo, "El monumento más importante del derccho señorial son los 
ticamente adscrito al Reino de León, y que posteriormente se incorporaría al de Castillahaya existido una "legislación" especial". Propiamente no puede hablarse de un sistema de instituciones jurídicas gallegas con la raigambre de los demás antiguos derechos forales peninsulares, como el aragonés, navarro o catalán, que, como es sabido, en un determinado momento histórico, ofrecieron una mayor resistencia al Derecho castellano".

Por lo que se refiere a su estructura socio-económica, entre las diversas notas caracterizadoras del pueblo gallego, tradicionalmente se ha venido señalando su acentuado ruralismo?

En este sentido, frente al campesinado libre de Castilla, que se asentó en el territorio conquistado como en un campamento, y al que le fueron concedidas diversas libertades a través de los correspondientes Fueros y Cartas Pueblas, los campesinos gallegos - al no vivir las circustancias de conquista y repoblación que provocaron el consiguiente florecimiento de los regímenes municipales con sus privilegios particulares y el derecho peculiar de la autonomía ciudadana-, sin embargo y por el contrario, vivieron hasta épocas más bien recientes sometidos a vínculos de carácter señorial, tanto eclesiásticos -que fueron los más numerosos- como nobiliarios, dando lugar en el concreto ámbito de la propiedad de la tierra, por ejemplo, a la paradójica persistencia de formas de entrega de tierras típicas de dicho régimen, como acredita la extensión en el tiempo del antiguo "foro" o censo agrícola".

Sólo la supresión de los señoríos, así como las desamortizaciones realizadas en el siglo XIX, posibilitaron la formación de la pequeña propiedad de la tierra en Galicia, a la que el campesinado gallego pudo acceder, fundamentalmente y en gran medida, a través del dinero conseguido a costa de la emigración hacia América". No obstante, el cambio operado en la estructura económico-social gallega, al haberse producido tan tardíamente, no llevó aparejada la necesidad de una nueva regulación jurídica, puesto que, a consecuencia del ya indicado retraso, le resultaba perfectamente aplicable el Derecho castellano entonces vigente de las Partidas y las Leyes de Toro ${ }^{10}$.

Fucros o Código concedido por el arzobispo Gelmírcz a la Tierra de Santiago con excepción de la urbe compostelana. Esta ciudad y otros núclcos urbanos recibieron fucros cspeciales de los señores, los soberanos y del propio concejo o municipio en régimen de consulado". En este sentido, "hay indicios de haberse extendido a Galicia y a la Ciudad, el Fuero territorial y municipal promulgado en Lcón. por Alfonso $V$, el año 1020. Compostela recibió de Ramón de Borgoña en 1095 un privilegio franco, y el hijo de aquél, Alfonso VI, en 1105, un fuero del mismo estilo. La penetración del derecho de francos en todos los territorios medievales, singulariza a determinadas ciudades y termina por generalizarse. Tras una revolución comunal en 1116. los burgueses de Compostela renovant leges et plebiscita. Alfonso $X$ el sabio en su política legislativa unificadora, otorgó fueros a la Tierra en 1252 y a la Ciudad en 1253 y 1261 . Todavía Alfonso XII, a quien debe la Corona de Castilla el sometimiento a la justicia del Rey, con cierto respeto para los fucros municipales en las ramas del derecho privado, pero radical unificación en el derccho penal, en el procedimiento y en la administración de justicia, hubo de resolver las antiguas cuestiones planteadas cntre el Concejo y el Señorío. Una historia semejante a la de Santiago y su Tierra se desarolló cn el resto de las tieras del señorío eclesiástico y laical".

5 El término scñalado es utilizado por CASTAN, La Compilación del Derecho Civil especial de Galicia, en RGLJ 46, 1963, (scparata) p.9.

6 FUENTESECA DIAZ, Prólogo cit., p.9.

7 GIBERT, El Derecho Civil de Galicia cit., p.538. Junto a la nota indicada, el autor citado tambićn destaca, en este caso en relación a la cultura jurídica de Galicia, la de "arcaismo", que, en su opinión, se da "desde la prehistoria hasta el presente".

8 Cfr. FUENTESECA DIAZ, Prólogo cit., p.8 s.; OTERO VARELA, Sobre la Compilación del Derecho foral gallego cit., p.555; RODRIGUEZ ENNES, Aproximación a la Historia jurídica de Galicia cit., p. 123 ss.

9 FUENTESECA DIAZ, op. cit., p.9; OTERO VARELA, op. cit., loc. cit. Respecto al proceso desamortizador operado en Galicia y el papel de la emigración en la formación de los patrimonios campesinos, cfi: RODRIGUEZ ENNES, Aproximación a la Historia juridica de Galicia cit., p.173 ss.. y bibliografía allí cit.

10 Así lo ha destacado OTERO VARELA, op. cit., p.555. 
La señalada inexistencia de una "legislación" especial en Galicia indujo a cuestionar en un momento posterior en el tiempo, particularmente importante para la historia jurídica europea, y por tanto española, como es la etapa codificadora, la posible condición de Galicia como uno de los posibles territorios de derecho foral a que, sin determinarlos, aludía el antiguo art.12 del Código Civil".

La polémica planteada en el ámbito doctrinal'2, que por aquel entonces tuvo una cierta importancia y que hoy queda como un mero vestigio o recuerdo histórico, se saldaría -no sin importantes discrepancias- considerándose con carácter general que "se puede hablar de un Derecho de Galicia e incluirlo en el cuadro del Derecho foral, entendido este en un sentido lato, y sobre todo se debe reconocer que existe un Derecho especial gallego, siquiera sea de carácter fundamentalmente consuetudinario" "13. Avalarían lo señalado, según el sector de la doctrina que defiende este planteamiento, determinadas disposiciones legales y administrativas dictadas con anterioridad y posterioridad al proceso codificador ${ }^{14}$.

Con independencia de estas precisiones y de las aludidas disposiciones-que, aun cuando puedan puedan servir para argumentar desde un punto de vista meramente legal o administrativo la posible condición de Galicia como territorio foral, en nuestra opinión, no dejan de presentar ciertas dudas razonables en cuanto a los posibles motivos de fondo a que respondieron ${ }^{15}$-, tradicionalmente se han venido señalando una serie de puntos de referencia a través de los cuales resultaría posible apreciar el desarrollo histórico del fenómeno jurídico en Galicia hasta la promulgación de la actualmente en vigor Ley 4/1995, de dereito civil de Galicia (en adelante, LDCG), en la que hoy se establece el marco normativo referencial del ordenamiento jurídico civil gallego ${ }^{16}$.

11 Inicialmente, artículo $5^{\circ}$ de la Ley de Bases del Código Civil de 11 de mayo de 1888 : "Las provincias y territorios en que subsiste derecho foral, lo conservarán por ahora en toda su integridad, sin que sufra alteración su actual régimen jurídico por la publicación del Código, que regirá tan sólo como supletorio en defecto del que lo sea cn cada una de aquéllas por sus leyes cspeciales..."

12 Tradicionalmente se vienen citando como ejemplos de la mencionada polémica las posiciones totalmente contradictorias sostenidas, respectivamente, por URENA, voz Derecho foral, en Enciclopedia Jurídica Española, tomo XI, s.f., p. 136 ss., e ISABAL, voz Derecho Civil de Galicia, en la misma obra, p.30 s. Así, mientras que para el primero Galicia no tendría la condición de territorio foral a que aludía, sin determinarlos, el antiguo art. 12 del Código civil, en opinión del segundo autor sí se daría tal circustancia.

13 CASTAN, La Compilación del Derecho civil especial de Galicia cit., p.9. Cfr., también en rclación a esta cuestión, la doctrina citada por el autor señalado en op. cit., p. $10 \mathrm{nt} .9$.

14 Entre las mismas se han señalado las siguientes: el Decreto de 2 de febrero de 1880 , a través del cual se procedió a modificar la Comisión General de Codificación, agregando un representante por Galicia: la Ley de Bases del Código civil, de 11 de mayo de 1888, que en su Base $13^{a}$ incluía a Galicia entre las legislaciones que habían de ser tomadas en consideración para incorporar al Código el mayor número posible de sus normas sobre servidumbres; el Real Decreto de 24 de abril de 1889 , que incluía a las provincias de Galicia, junto a las de Cataluña, Aragón, Navarra. Vizcaya y Mallorca, al determinar cuáles habían de ser las Comisiones especiales encargadas de redactar los proyectos de ley en que se contuvieran las instituciones forales que convenía conservar; y, finalmente, la Orden de 10 de febrero de 1948 , que, en aplicación do lo dispuesto en el Decreto de 23 de mayo de 1947, designó entre las nuevas Comisiones, la correspondiente a Galicia. Cfr. CASTAN, La Compilación del Derecho civil especial de Galicia cit., p.9 s.; LETE DEL RIO, El Derecho civil de Galicia, en Manual de Derecho civil gallego, VV.AA., 1999, p.21 ss.

15 Cabe preguntarse, por cjemplo, cuál es la razón sustancial por la que aun siendo conscientes de la existencia de muy "pocas divergencias con el Derecho General de España" -como se recogería en la Memoria elaborada con posterioridad por el representante gallego, Sr. López Lago, y publicada cn Madric en 1885, donde se scñalaba que las dos únicas especialidades del Derecho de Galicia a incluir en el Código Civil eran los foros y la compañía familiar- se incluyese a Galicia entre los considerados como territorios forales; iinfluyó en ello de alguna forma la condición de gallego del entonces Ministro de Justicia, Sr. Alvarez de Bugallal?. Por otra parte, también llama la atención la circustancia de que en la citada Base $13^{2}$ de la Ley de Bases de 11 de mayo de 1888 , se aluda textualmente a "la incorporación al Código del mayor número posible de disposiciones de las legislaciones" de diversos territorios, incluyendo entre los mismos a Galicia, carcnte, por lo demás, de cualquicr legislación.

16 Dicha Ley, como es sabido, no es la única norma del Derecho civil gallego. También se encuentra integrado por otra serie de Leyes, en este caso especiales, entre las que cabe citar las siguientes: Ley de 22 de junio de 1983, de fundaciones de interés gallego (reformana por Ley de 8 de noviembre de 1991); Ley 
El análisis de dichos puntos de referencia, a nuestro juicio, permite extraer sintéticamente, desde una visión general y de conjunto de los mismos, dos consideraciones respecto al proceso operado: por una parte, la lenta y progresiva precisión y ampliación, realizada por la doctrina a lo largo del tiempo, del contenido del denominado "Derecho civil propio y singular" o "Derecho especial gallego"18, caracterizado fundamentalmente, según se ha señalado, por tratarse de un derecho consuetudinario, integrado por ciertas "peculiaridades jurídicas", lo que, desde antiguo y en virtud de tal carácter, provocó hasta su fijación por escrito una notable incertidumbre en cuanto a la determinación de sus posibles "instituciones", así como dificultades respecto a la prueba de las mismas $1 \%$; , por otra, la paulatina y progresiva concienciación por parte de un sector cada vez más importante de juristas gallegos en cuanto a la existencia, defensa y potenciación de un Derecho (consuetudinario) considerado como propio.

En ese desarrollo histórico señalado, tras un largo y lento proceso, muy tardíamente, en concreto, el 2 de diciembre de 1963 aparecería el que se presenta como primer texto normativo oficial en el que se recogían determinadas figuras específicas de Galicia: Ia Compilación del derecho civil especial de Galicia.

Dicha Compilación no obtuvo un juicio unánime en su momento, señalándose opiniones contradictorias, tanto por lo que respecta a la oportunidad de su realización, como en relación a su contenido.

Así, por lo que se refiere al primero de los aspectos señalados, algunos de los autores que escribian en aquel tiempo, destacaban que la citada Compilación de 1963, supuso la fijación por escrito en normas claras y concretas del derecho consuetudinario que vagaba disperso en Acuerdos de la Real Audiencia ${ }^{20}$, obras de los

de 28 de diciembre de 1984 , del estatuto gallego del consumidor y usuario; Ley de 20 de julio de 1988, de ordenación del comercio interior de Galicia; Ley de 10 de noviembre de 1989 , de montes vecinales en mano común; Ley de 16 de abril de 1993, de aparccrías y arrendamientos históricos gallegos; Ley de 15 de julio de 1993, de recurso de casación en materia de Derecho civil especial de Galicia: Ley de 9 de junio de 1997 , de familia, de la infancia y de la adolescencia; Ley de 21 de agosto de 1997, de ordenación y promoción del turismo en Galicia; Ley de 18 de diciembre de 1998, de cooperativas de Galicia.

17 Denominación ésta utilizada, según LETE DEL RIO, El Derecho civil de Galicia cit., p.21, por la antigua doctrina.

18 Emplean esta denominación, por cjemplo, FUENTESECA, Prólogo cit., p.8, y CASTAN, La Compilación del Derecho civil especial de Galicia cit., p.9.

19 Cfr., incidiendo cspecialmente en esta característica distintiva, entre otros, GIBERT, El Derecho civil de Galicia cit., p.539 s., y CASTAN, La Compilación del Derecho civil especial de Galicia cit., p.14 s.

20 Entre las referencias más antiguas del derecho en Galicia se vienen citando escasísimas fuentes escritas de base judicial que recogerían las prácticas de la Real Audiencia de Galicia.

Respecto a la antigua situación de la justicia en Galicia, GIBERT, en El Derecho civil de Galicia, cit., p.539, ha indicado sintéticamente: "En 1480, los Reyes Católicos restablecieron enérgicamente la autoridad y la justicia del Rey, que en todo el siglo anterior habían decaido notablemente. Un ministro del Consejo Real y un Oidor de la Chancillcría fueron enviados para poner orden en el reino de Galicia, agitado por las violencias scñoriales y las guerras privadas. En 1494 se enviaron Alcaldes Mayores que, junto con el Gobernador ejerciesen la jurisdicción civil y criminal, con una carácter de Audiencia regia: es decir, cn los casos de apelación, en los casos de corte y en todos los demás que se produjesen en una proximidad local al tribunal. Quedó muy reducida la apelación a la Audiencia de Valladolid, que era única en la Corona de Castilla, hasta que en 1504 se fundó la de Ciudad Real, en seguida trasladada a Granada y convertida en segunda chancillería de los Reinos. A diferencia de la estabilidad que había logrado la Audiencia de Valladolid, nómada también en sus comienzos, debían los micmbros de la Audiencia de Galicia andar por ciudades, villas y lugares para administrar justicia. Felipe II la reorganizó tras Ins visitas de 1564 y 1566 , haciéndola más estable; sustituyó el gobernador por un Regente lctrado. Pero había en el Reino muchos pobres (todos los gallegos dicen que son pobres) que no podían desplazarse hasta la Audicncia a pedir justicia, y se permitió que la administrasen los Alcaldes cuando salían para realizar alguna comisión". Según GIBERT, op. cit., loc.cit., "Acaso este contacto con los lugares tiene que ver con cl vigor de los usos locales y del derecho consuetudinario, que es el carácter fundamental del derccho en Galicia".

En relación a la Real Audiencia de Galicia, cfr. RODRIGUEZ ENNES, Aproximación a la Historia jurídica de Galicia cit., p.71 ss., y bibliografía allí cit.

402 
tratadistas $^{21}$ y costumbres locales que había que acreditar en cada caso particular, posibilitando que las instituciones jurídicas -anteriormente encubiertas bajo formas de ficción- que en ella se regulaban, y que tenían por finalidad salvaguardar el patrimonio familiar, volviesen a tener su antiguo esplendor y se desarrollasen naturalmente, amparadas por una regulación que evitaría muchos pleitos y facilitaría la resolución de los que se promoviesen ${ }^{22}$. Dicho juicio favorable referido a la Compilación gallega se enmarcaría dentro de otro más general, relativo a la valoración positiva del movimiento por aquel entonces dirigido a la compilación de los diversos derechos forales, respecto del cual se indicaba que debía "ser considerado, ya no como fue el derecho foral frente a la Codificación unitaria decimonónica, una resistencia y una reacción conservadora, sino más bien como un impulso hacia adelante en la esfera jurídica privada", revelándose en el fondo las instituciones consideradas simplemente arcaizantes y estacionarias, en el régimen económico de la familia y de las sucesiones, o bien en la propiedad y en la explotación campesina y agraria, en su enorme fuerza positiva y creadora ${ }^{23}$.

Otros autorizados juristas gallegos, sin embargo, no pensaban lo mismo, $y$, expresándose de forma contundente, dirigieron severas censuras a lo que consideraron como un "intento de inoportuna resurrección de un Apéndice foral de Galicia"

Las discrepancias doctrinales, también se manifestaron vivamente en cuanto al contenido de la Compilación.

Para un sector de la doctrina, aun admitiendo que pudiera haber sido más reducido el número de los artículos recogidos en dicho texto normativo -simplificando sobre todo los relativos a figuras en trance de desaparición como los foros, subforos y gravámenes análogos, cuya inclusión en el cuerpo señalado era criticada por su anacronismo, no parecía probable que en la Compilación, estructurada en su opinión en normas escri-

21 Lucas Cortés, el anticuario del Derecho en el s.XIX, señalaba como úníca obra de derecho gallego las Ordenanzas de la Real Audiencia del reino de Galicia, publicadas por J. Maldonado y Pardo en 1679, en La Coruña. Más adelante, en 1768, aparecerá otra obra titulada Derecho práctico y estilos de la Real Audiencia de Galicia, de la que existe una segunda edición anotada y reimpresa en Santiago en el año 1844 reeditada por el Ilustre Colegio Provincial de Abogados de La Coruña en el año 1975.

Como instituciones peculiares de la Real Audiencia figuraban, por una parte, el denominado "auto gallego", calificado cn aquellos momentos como "Ia mejor alhaja que tiene el Rey en el reino de Galicia" y que se presentaba como una especie de interdicto de recobrar, establecido con lia finalidad de poder defender a los labriegos de los despojos de la nobleza, por otra, la "graciosa", considerada como "una equidad cn favor del deudor, para que recupere los bienes raices que se le hayan vendido cn subastación, aportando el importe de la venta". Vid. GIBERT, El Derecho Civil de Galicia cit., p.540.

22 CASTAN, La Compilación del Derecho civil especial de Galicia cit., p.23.

23 GIBERT, El Derecho Civil de Galicia cit., p.537.

24 Así, por ejcmplo, el ilustre notario gallego Luis MOURE MARIÑO, manifestaba en un artículo titulado El Apéndice foral de Galicia, publicado en el diario ABC el 27 de noviembre de 1963. del que se hacía eco CASTAN en La Compilación del Derecho civil especial de Galicia cit., p.24 s., lo siguiente: "Casi a los setenta y cinco años de vigencia de ese Código (cl Código civil español) -en cuyo articulado hay la necesaria flexibilidad para atender las más variadas situaciones, aparte del cúmulo de doctrina que cn torno al mismo ha elaborado la jurisprudenciá-, casi a los tres cuartos de siglo del Código civil, los gallegos no salimos de nuestro asombro al ver surgir en el horizonte jurídico de la región, arcaico y renqueante, un abuelo inesperado: nos referimos al Apéndice de Derecho foral de Galicia, resucitado ahora, precisamente en un momento histórico en que, por imperativo de factores socio-cconómicos incoercibles, la vida rural galleoa está dando -si es que no lo ha dado ya- un viraje de noventa grados. Hablar en Galicia a estas alturas de foros o de fantasmas -como la famosa "compañía familiar gallega"- es lo mismo que dotar de armaduras de cota de malla a los soldados de la Era atómica. (La tierra está siendo abandonada. Hace unos años buscaban los hijos la mejora. Hoy ni siquiera la mejora ofrecida a los hijos es bastante para retenerlos al frente de la hacienda familiar). Por eso, sacar ahora a la escena estas antiguallas arqueológicas, precisamente en vísperas del Plan de Desarrollo - cuando quienes nos ocupamos de cuestiones económicas meditamos en reformas sustanciales de las estructuras agrarias y del sistema de propiedad-, es algo que, por fuerza, debemos de incluir en el cuadro de lo rechazable". Contra tales afirmacioncs, vid. CASTAN, op. cit., p. 25 ss. 
tas, claras y concretas, faltasen -según defendían diversos juristas gallegos- instituciones que hubiesen debido incluirse, como el "contrato de vitalicio" o el "usufructo universal en favor del cónyuge viudo"

El criterio sostenido por otros autores -extensivo al denominado "Derecho civil de Galicia" en general-, por el contrario, era mucho más radical, por entender que en la llamada Compilación del Derecho foral gallego se recogían una serie de figuras -el foro, la compañía familiar, la aparcería, etc.- que, en conjunto, no parecían tener entidad suficiente como para poder justificar su recopilación, ni para constituir el problema jurídico de Galicia, que, a su entender, se concretaría en la dificultad de aplicación del Código Civil a un ambiente impropio, al especial ambiente económico gallego, fundamentalmente rural y basado en la existencia de una pequeña propiedad desgajada de los antiguos señoríos en unidades de tipo "lugar" poseidos por los colonos. Dicho problema, probablemente se resolvería, según se decía, con un cambio del ambiente gallego, simplemente por medio de una ordenación económica de tipo actual, o bien, mediante una pequeña modificación del duro dogmatismo del Código Civil, especialmente en materia de Derecho patrimonial familiar y sucesiones, que no hiciera necesario recurrir a una serie de formas indirectas o fraudulentas -introducidas principalmente por la vía notarial con la finalidad de conseguir la indivisión del patrimonio, la viudedad, el testamento mancomunado, la delegación de la facultad de mejorar, etc.-, elaboradas para hacer posible la vida jurídica de una organización económica y familiar como la de aquél entonces en Galicia ${ }^{26}$.

En cualquier caso, el juicio que prevaleció entre los tratadistas posteriores respecto a la Compilación de 1963, olvidando en muchas ocasiones las condiciones políticas y jurídicas que se dieron en el contexto histórico en que se gestó la misma ${ }^{27}$, fue, en esencia, un juicio totalmente negativo ${ }^{2 x}$. Dicha valoración, ha quedado reflejada en la propia Exposición de Motivos de la actualmente vigente LDCG, en la que se califica al citado Texto normativo como "fragmentaria, incompleta, falta de entidad propia de un sistema jurídico y, en consecuencia, en buena parte, de espaldas a la realidad social",

En 1987 se procedió a adoptar e integrar la Compilación de 1963 en el ordenamiento jurídico de la Comunidad gallega a través de la Ley 7/1987, de 10 de novicmbre, del Parlamento de Galicia, bajo el título de "Compilación del Derecho Civil de Galicia", suprimiendo el antiguo adjetivo de "especial", que figuraba en la anterior denominación del texto del año 1963, introduciendo en el mismo una serie de modificaciones "exigidas por la falta de armonía constitucional y estatutaria de algunos de sus preceptos", según se indicaba en su Exposición de motivos, así como por la falta de vigencia de algunas de las instituciones contenidas en aquélla, como por ejemplo ocurría en el caso de los foros ${ }^{24}$.

25 CASTAN, La Compilación del Derecho civil especial de Galicia cit., p.27 s.

26 OTERO VARELA, Sobre la Compilación del derecho foral gallego cit., p.555 s. Cfi., del mismo autor, también en sentido crítico, en este caso en relación a la vigente LDCG, Jurisprudencia bromeando en serio, en Dereito, vol. núm.1, 1998, p.155 ss

27 Así lo destacaba, y creemos que éste es un dato importante a tener en cuentál para poder realizar una valoración lo más adecuada y correcta posible del mencionado texto normativo, REBOLLEDO VARELA, en El desarrollo del Derecho civil gallego, recogido en La modernización del Derecho civil, VV.AA., 1994. p. $186 \mathrm{~s}$.

28 Cfr, en este sentido, entre otros, por ejemplo, REBOLLEDO VARELA, El descurrollo del Derecho civil gallego cit., p. 184 ss.; BELLO JANEIRO, La Ley 4/1995, de 24 de mayo, de Derecho civil de Galicia. en RJN, núm.14, 1995, p.19 ss.; ID, El ejercicio de la competencia en materia civil por la Comunidad Autónoma Gallega, 1999, p.71 ss.; LETE DEL RIO, El Derecho civil de Galicia cit., p.25 s.

29 Todo ello, sceún LETE DEL RIO, El Derecho civil de Galicia cit, p.27, implicaba la adopción de un critcrio autonomista, sancionando legislativamente el carácter de "Derecho común" del Derecho civil de 
Todo ello resultó posible porque, como es sabido, la Constitución española de 1978, como reflejo del cambio político y jurídico producido a partir de 1975, en su art. 149/1.8, tras atribuir competencia exclusiva al Estado sobre la legislación civil, también reconoció una cierta capacidad legislativa en materia civil a los Parlamentos de determinadas Comunidades Autónomas, permitiéndoles realizar a través de los cauces parlamentarios correspondientes, la conservación, modificación y desarrollo de su propio derecho civil, en tanto dicho derecho propio fuese preexistente al momento temporal de la promulgación del texto constitucional.

Precisamente la circustancia de que Galicia se encontrase entre las Comunidades históricas del Estado español que contaban con un derecho civil foral o especial con anterioridad a la entrada en vigor de la Constitución -recogido en este caso en la Compilación de 1963-, permitió que la propia Comunidad Autónoma gallega, en el marco de las competencias que constitucionalmente le habían sido reconocidas, asumiese con carácter exclusivo y excluyente -al igual que se hizo en otras Comunidades Autónomas históricas, como la Aragonesa, la Navarra, la Balear, la Vasca o la Catalanaen el art.27.4 de su Estatuto de Autonomía, la "conservación, modificación y desarrollo de las instituciones del Derecho civil gallego" a través de su propio Parlamento autonómico. De esta forma, los denominados Derechos civiles forales o especiales, y, entre ellos, por lo que aquí interesa, el gallego, considerados hasta entonces como conjuntos de normas de carácter excepcional frente al Código civil, pasaron a convertirse en el plano "personal" en Derecho común de los respectivos territorios y, por tanto, de aplicación prioritaria, además de tener la posibilidad de autointegración y desarrollo a través de sus propios principios generales ${ }^{30}$.

El proceso histórico jurídico gallego se cierra momentaneamente en una fecha reciente con la vigente Ley 4/1995, de 24 de mayo, de dereito civil de Galicia -que deroga la anteriormente señalada Ley del Parlamento de Galicia de 10 de noviembre de 1987, sobre la Compilación del derecho civil de Galicia-, en la que, como se ha indicado, se establece el actual marco normativo referencial del ordenamiento jurídico-civil gallego.

Galicia, cntendiendo por éste no sólo el compilado, con la importante consecuencia de considerar a la costumbre local como fuente del Derecho gallego, subordinada a las normas del texto compilado, pero de aplicación preferente al Código civil y a las demás Leyes del Estado. No obstante, en opinión del indicado autor op. cit., loc. cit., la mencionada Ley $7 / 1987$, incurría en cierta incongruencia, al señalar en su Disposición final primera que "las normas de Derecho civil de Galicia, escrito o consuetudinario, vigentes al promul garse la Compilación de 1963, se sustituyen por las contenidas en ella", olvidando que el Prcámbulo había anunciado una nueva Ley de Derecho civil gallego desarrollado desde "una línea abiertamente constitucio nal y nítidamente autonomista", renovando las disposiciones compiladas y entroncándolas con aquellas olras no compiladas. Cfr., también, en relación a la citada Ley 7/1987, BELLO JANEIRO, La Ley 4/I995, de 24 de mayo, de Derecho civil de Galicia cit., p.24 ss.; ID, El ejercicio de la competencia en materia civil cit. p.79 s.; LORENZO MERINO, El Derecho civil de Galicia y la Propuesta de Compilación del 22 de narzo de 1991,1992 , p.16 ss.

30 LETE DEL RIO, El Derecho civil de Galicia cit., p.27. Respecto al alcance de la naturaleza y el ámbito de aplicación de las normas contenidas en la LDCG, consideradas desde una perspectiva de conjunto, cfr. PENA LOPEZ, Precisiones complementarias para la aplicación del Derecho civil gallego a la luz de la doctrina del Tribunal Constitucional, en Actualidad Civil, 1994, p.909 ss.; ID., Consideración del derecho foral como Derecho común.El sistema autónomo de derecho civil común gallego, en Actualidad Civil, núm. 46, 1995, p. 925ss; ID., El ámbito material del derecho foral, con particular consideración del ámbito de aplicación del Derecho civil gallego, en Rev. de la Facultad de Derecho de la Universidád Complutense de Madrid. núm.85, 1995, p.1 ss.; ID. O ámbito material do dereito foral, con particular consideración do ámbito de aplicación do Dereito civil galego, en Dereito civil de Galicia (Comentarios á Lei $4 / 1995$ do 24 de Maio), VV.AA, s.f., pero 1996, p.77 ss.; ID., Comentario a los arts. $1^{\circ}$ a $3^{\circ}$ de la LDCG en Comentarios al Código Civil y Compilaciones Forales, dirigidos por ALBADALEJO y DIAZ ALABART, Tomo XXXIl, vol 10, 1997, p.7 ss. 


\section{LA LEY 4/1995, DE 24 DE MAYO, DE DEREITO CIVIL DE GALICIA.}

El vigente cuerpo normativo encuentra su origen más mediato en dos Trabajos previos de reforma de la Compilación elaborados, respectivamente, por algunos miembros de una extinguida Comisión Parlamentaria no permanente, constituida en el transcurso de la II legislatura, el día 9 de mayo de 1988, presentado en el Parlamento gallego con fecha de 22 de marzo de 1991, y el formulado por el Consello da Cultura Galega, también aportado al Parlamento de Galicia, con fecha de 11 de junio de 19913!.

En dichos Trabajos prelegislativos, calificados como "dificilmente conciliables por responder a planteamientos ideológicos y jurídicos diversos" ${ }^{32}$, cabe destacar que se pueden apreciar dos distintas concepciones en relación a dos cuestiones trascendentales. Por una parte, la relativa a la posible forma que debería de adoptar el desarrollo del Derecho civil gallego, concretada en la siguiente pregunta: ¿ha de optarse por desarrollar un Derecho civil para Galicia, autonomista y de futuro, o, más bien, por un Derecho civil propio de Galicia, foralista y basado en el pasado tradicional ${ }^{33}$, o, en otros términos, ¿ha de mantenerse el denominado "Derecho foral tradicional gallego", recibido y concretado en diversas instituciones o figuras típicas, -como por ejemplo, "a veciña", los "muiños de herdeiros", la "compañía familiar galega", o el "testamento por comisario"-, o, por el contrario, ha de suprimirse por su carácter anacrónico?; por otra parte, la cuestión referente al posible rango jerárquico que debería de ocupar la costumbre en el sistema de fuentes normativas del Derecho gallego ${ }^{34}$.

Sobre la base de los dos Trabajos citados se elaboraría con posterioridad una Proposición de Ley, presentada y asumida por unanimidad por todos los grupos políticos con representación parlamentaria, con fecha de 21 de abril de 1993, que decaería por disolución de la Cámara. En dicha Proposición de Ley, al igual que en otra posterior, de 22 de junio de 1994, no se acogería un único criterio, sino que, procurando respetar ambos Trabajos prelegislativos, se procedió a yuxtaponer las específicas instituciones que en ellos se demandaban ${ }^{35}$.

Esta actitud ecléctica, que, como se puede suponer, daba lugar a diversas ambiguiedades, contradicciones y discordancias, resultaría relativamente superada, según un sector doctrinal, en el precedente más inmediato de la Ley: el Informe de la

31 Los aludidos Trabajos se encuentran recogidos en Foro Galego, núm.184, 1992, p. 13 al 37 y 39 a 59 , respectivamente. Sobre el Trabajo presentado por la extinguida Comisión Parlamentaria no Permanente, su evolución y conclusión, vid. LORENZO MERINO, Un Derecho civil para Galicia. La propuesta legislativa de Compilación de derecho civil de 22 de marzo de 1991, en La Ley, núm.2995, p.1; ID., El Derecho Civil de Galicia y la Propuesta de Compilación del 22 de marzo de 1991 cit., p. 7 ss. Cfr., también, una crítica al texto presentado por el Consello da Cultura Galega, así como a la Proposición de Ley de 27 de abril de 1993, en SANDE GARCIA, O Dereito civil de Galicia: Unha actualización imposible á luz da historia, en La modernización del Derecho civil cit., p. 147 ss.

32 REBOLLEDO VARELA, A reforma da Compilación de 1963 e ofuturo do Dereito civil de Galicia, en Rev. Xurídica Galega, núm.2, 1992 , p.387 ss.; ID., Prólogo a su edición de la Compilación Galega, cn Compilaciones y Leyes de los derechos civiles forales o especiales, 1993; ID., El desarrollo del Derecho civil gallego cit., p. 183.

33 REBOLLEDO VARELA, El desarrollo del Derecho civil gallego cit., p. 183.

34 LORENZO MERINO, Prólogo a la $L D C G$, en Ley de Derecho Civil de Galicia, 1996, p.23. Cfr., además, en sentido crítico, respecto a la mencionada cuestión, que se proyecta en la LDCG, DIAZ FUENTES, Dereito Civil de Galicia (Comentarios á Lei 4/1995), 1997, p.20 ss.; LETE DEL RIO, El Derecho civil de Galicia cit., p.33 s.

35 En relación a las citadas Proposiciones de Ley, cfr., por ejemplo, las diversas apreciaciones realizadas, entre otros autores, por REBOLLEDO VARELA, El desarrollo del Derecho civil gallego cit., p.183 ss.; LORENZO MERINO, Prólogo a la LDCG cit., p.23; LETE DEL RIO, El Derecho civil de Galicia cit., p.28. 
Ponencia de Derecho civil, y el correspondiente Dictámen de la Proposición de Ley de Derecho civil de Galicia, presentado a iniciativa de los grupos políticos Partido Popular de Galicia, Socialistas de Galicia y Bloque Nacionalista Galego, que sería aprobado por unanimidad en el Parlamento de Galicia, reunido en Sesión plenaria el día 20 de abril de 1995. En el mismo, en opinión del aludido sector doctrinal, en diversas instituciones relativas a las materias de contratos, comunidades, servidumbres y régimen sucesorio, los miembros de la Ponencia y los expertos convocados al efecto alcanzaron a través de posiciones de síntesis una cierta concordancia ${ }^{36}$.

La nueva y esperada LDCG, en la que, como se ha indicado, no se resuelve definitivamante la cuestión de la polémica planteada en torno al "autonomismo" o "foralismo", consta de ciento setenta artículos, estructurados en nueve Títulos -uno Preliminar y otros ocho atinentes a materias relativas al Derecho de personas (ausencia y "a veciña"), Derechos reales (comunidades, servidumbres, serventías, "cómaro" y retracto de graciosa), Contratos (arrendamiento rústico, aparcerías, vitalicio y compañía familiar), Derecho de familia (régimen económico familiar), Derecho de sucesiones (pactos sucesorios, legítimas, sucesión testada e intestada y partición)-, a los que precede una Exposición de motivos, y se añaden dos Disposiciones Adicionales, cuatro Transitorias, una Derogatoria y una Final que la cierra.

En el citado Texto normativo, el legislador gallego, en su atán por contemplar e incluir todas las posibilidades jurídicas que se pudiesen producir en la realidad gallega, ha querido conservar, salvo el "foro", todas las instituciones de clara raigambre consuetudinaria que se encontraban recogidas en la antigua Compilación de Derecho Civil Especial de Galicia, de 2 de diciembre de 1963 -como por ejemplo, "a veciña", el "cómaro", "ribazo" o "arró", las "agras" o "vilares", las "augas de torna a torna" o "pilla pillota", la "compañía familiar gallega", los "muiños de herdeiros", etc.; algunas de las cuales, con indudable valor etnográfico o antropológico, pueden presentar hoy en día una escasa efectividad real-, complementando la conservación de dichas instituciones con la introducción de otras figuras jurídicas e instituciones novedosas, que venía demandando la realidad social y jurídica gallega, en un afán por intentar superar las carencias legislativas que el derecho propio de la Comunidad gallega había venido sufriendo a lo largo de su historia, y que, según se dice, le habían sido negadas por el Derecho civil común. Así se ha hecho, por ejemplo, con el tratamiento dado a los arrendamientos rústicos, la regulación del contrato de vitalicio, el establecimiento de un nuevo régimen en materia de sucesiones, o la regulación de la servidumbre de paso y serventías en la vigente LDCG.

Precisamente en atención a esta segunda posibilidad legislativa reconocida constitucionalmente en el ámbito civil autonómico, que se concreta en el término "desarrollo del derecho propio preexistente a la Constitución", se han planteado y todavía se plantean importantes problemas interpretativos, en particular por lo que se refiere al específico alcance que se deba dar en cuanto a su significado a dicho controvertido término, sobre todo, en aquellos supuestos en los que la Comunidad Autónoma de que se trate, amparándose en dicha potestad legislativa civil, introduzca instituciones o preceptos que, sin contar con un precedente inmediato recogido en la Compilación correspondiente, puedan invadir las competencias exclusivas del Estado en materia de Derecho civil ${ }^{37}$.

36 Así lo entiende LORENZO MERINO, Prólogo a la LDCG cit., p.23.

37 Según un sector de la doctrina, la referida posibilidad legislativa, reconocida por el art. 149/1.8 de la Constitución española de $1978 \mathrm{en} \mathrm{el} \mathrm{ámbito} \mathrm{civil} \mathrm{autonómico,} \mathrm{encontraría} \mathrm{su} \mathrm{límite} \mathrm{en} \mathrm{las} \mathrm{normas} \mathrm{de} \mathrm{apli-}$ cación general y dirccta contenidas en el referido precepto constitucional in fine, sin que ello implique nccesariamente -apoyándose en la interpretación realizada por el Tribunal Constitucional con ocasión del planteamiento de determinados recursos de inconstitucionalidad en sus sentencias 121/1992, de 28 de septiembre, 182/1992, de 16 de noviembre, 88/1993, de 6 de mayo- la obligación por parte de los Parlamentos 
Ciñéndonos al concreto ámbito normativo autonómico gallego, la doctrina jurídica que se ha ocupado del análisis y estudio de la LDCG -hasta el momento presente todavía no recurrida por el Gobierno central bajo alegación de inconstitucionalidad ${ }^{3 \mathrm{~B}}$-, ha destacado en relación a la misma, una serie de aciertos o logros que, con carácter general, se concretarían fundamentalmente, entre otros, en la introducción y regulación de una serie de instituciones o figuras no compiladas en 1963 -como, por ejemplo, el vitalicio, el usufructo universal a favor del cónyuge viudo, el "apartamiento", el testamento mancomunado o el testamento por comisario-, el aludido establecimiento de un sistema sucesorio propio con amplitud de pactos, así como la también señalada nueva regulación sobre arrendamientos rústicos, sancionando la libertad de pacto en cuanto a las rentas y la duración del contrato ${ }^{33}$.

La existencia de normas de muy dudosa constitucionalidad, la inexplicable repetición de artículos en el texto legislativo, la introducción de preceptos supérfluos que se limitan a reproducir artículos del Código civil, la regulación vaga y ambigua de algunas materias, presentados como ejemplos de defectuosa técnica legislativa, así como también la preservación o introducción de algunas fïguras tradicionales de dudosa pervivencia en la actualidad, se vienen señalando, entre otros, como posibles errores o desaciertos contenidos en la $\mathrm{LDCG}^{4 t 1}$.

Esas carencias e imperfecciones, como es lógico, dan lugar a que el citado Texto normativo no se pueda presentar como cerrado ni completo, algo que, por lo demás, es materialmente imposible de cumplir para cualquier norma, por perfecta que la misma pudiese parecer. Resulta, por ello, necesario completar y corregir tales carencias e imperfecciones, así como también desarrollar ese derecho propio al hilo de las nuevas necesidades que día a día va demandando la cambiante sociedad gallega.

Siendo consciente de tales circustancias, el legislador gallego, prescribe con notable acierto - al igual que ya se hizo en su momento en la anterior Compilación de

autonómicos de tener que ceñirse, en el ejercicio de su capacidad legislativa civil reconocida constitucionalmente, exclusivamente a las instituciones históricas o consuetudinarias recogidas en sus antiguas Compilaciones de Derecho civil foral o especial, argumentándose al respecto que "si bien las Compilaciones han de ser el punto de partida sin que el desarrollo de los llamados históricamente Derechos forales pueda suponer su extensión a instituciones ajenas, sí es posible el complemento de la regulación de instituciones propias forales, lo que podrá implicar la aplicación del régimen foral a instituciones conexas con las privativas cuando los principios forales y la realidad social del territorio foral impongan una disciplina particular. Vid. REBOLLEDO VARELA, Los derechos reales en la Ley 4/1995 de 24 de mayo, de Derecho civil de Galicia (Montes vecinales en mano coman, aguas, servidumbre de paso y serventía), 1999, p.126.

En relación al marco constitucional y estatutario de la competencia nutonómica cn matcria civil, con carácter gencral, vid., por todos, BELLO JANEIRO, La Ley 4/I995 de 24 de mayo, de Derecho civil de Galicia cit., p.10 ss.; ID, El ejercicio de la competencia en materia civil por la Comunidad Autónoma Gallega cit., p.19 ss., y bibliografía allí citada.

38 Como indica REBOLLEDO VARELA, Los derechos reales en la Ley 4/1995 de 24 de mayo, de Derecho civil de Galicia cit., p.126 y nt.176, y ésta es una matización importante, la circustancia señaladal no impide que, conforme a lo dispuesto en el art.35 de la Ley Orgánica 2/1979, de 3 de octubre, cualquier Juez o Tribunal gallego pueda plantear cuestión de inconstitucionalidad en relación a determinadas normas o instituciones recogidas en la LDCG, que presenten un carácter conflictivo desde el punto de vista competencial, por invasión de las competencias cxclusivas del Estado en materia de derecho civil y exceso del Parlamento gallego en el ejetcicio de sus competencias en la conservación, modificación y desarrotlo del Derecho civil propio.

39 Cfr., entre otros, con carácter general, BELLO JANEIRO, La Ley 4/1995, de 24 de mayo, de Derecho civil de Galicia cit, p.26 ss.; ID., El ejercicio de la competencia en materia civil cit., p.83 ss.; AA.VV., Dereito civil de Galicia (Comentarios á Lei 4/1995 do 24 de Maio) cit., p.1l ss.; LORENZO MERINO, Prólogo a la LDCG cit., p.23 ss.; DIAZ FUENTES, Dereito civil de Galicia cit., p. 19 ss.; VV.AA., Comentarios al Código civil y Compilaciones Forales, 1997, tomo XXXII, 2 vols.; LETE DEL RIO, El Derecho civil de Galicia cit., p.30 ss.

$40 \mathrm{Cfr}$ : obras citadas en la nota anterior. 
$1963^{41}$ - en la Disposición Adicional segunda de la propia LDCG que "cada cinco años . como máximo -el subrayado es nuestro-, sin perjuicio de la iniciativa parlamentaria correspondiente, la Mesa del Parlamento de Galicia designará una Ponencia, integrada por miembros de los diversos grupos parlamentarios de la Cámara, a fïn de elaborar un informe comprensivo de las dificultades y dudas que se adviertan en la aplicación de los preceptos de la presente Ley y de aquellas normas que se estimen necesarias para la conservación, modifícación y desarrollo de las instituciones del derecho civil propio de Galicia".

Paradójicamente y a pesar de lo indicado, aun existiendo dicha consciencia de una serie de dificultades y dudas -ciertamente constatables-advertidas en la aplicación de los preceptos de la presente LDCG, se puede sostener con carácter general que, hasta el momento presente, el legislador gallego no ha tomado la iniciativa, como quizá hubiera sido lo deseable, con la finalidad de proceder a resolver los problemas suscitados en torno a determinadas instituciones que conforman su propio Derecho; todavía no se ha formulado al respecto iniciativa parlamentaria alguna, ni la Mesa del Parlamento de Galicia tampoco ha procedido a designar Ponencia alguna que elaborase el correspondiente informe de conjunto a que se alude en la indicada Disposición Adicional segunda de la LDCG.

Se ha preferido, eso sí, esperar a que transcurriese el plazo máximo de cinco años, establecido con carácter meramente indicativo en la Disposición adicional referida. En este sentido, la Xunta de Galicia, con evidente acierto, pero, en nuestra opinión, también con cierto retraso, ha decidido volver a poner en funcionamiento la denominada "Comisión Superior para el estudio y desenvolvimiento del Derecho civil gallego", que fue creada a través del decreto $71 / 1984$, de 23 de febrero, inicialmente adscrita a la Consellería de la Presidencia, y que nació con la finalidad -según se indicaba en el mencionado Decreto- de "ser el eje y motor del específico derecho gallego y dar así cumplimiento a lo dispuesto en el art.27.4 y $5^{\circ}$ del Estatuto de Autonomía, que atribuye a la Comunidad Autónoma la competencia exclusiva en esta materia".

Mediante el Decreto 107/1999, de 8 de abril, cuyo contenido deroga el del anterior Decreto señalado, se procede a adaptar la composición de la citada Comisión, según se señala, al nuevo marco competencial generado con la creación de la Consellería de

41 En la Disposición adicional de la Citada Compilación de 1963, se señalaba textualmante: "La Comisión compiladora formulará cada diez años una Memoria comprensiva de las dudas y dificultades que haya originado la aplicación de los preceptos de la presente Compilación, así como de las omisiones o deficiencias observadas, elevando al propio tiempo, si procediera, el oportuno proyecto de reforma".

Precisamente en cumplimiento de lo establecido en dicha Disposición adicional, en el mes de octubre de 1972, se celebró un I Congreso de Derecho Gallego, cuyo objetivo principal se centró en lí posible revisión de la Compilación de 1963, prevista para 1973, así como en intentar recoger la realidad socioeconómica del país gallego, rectificando en lo que procediese y tendiendo a la inclusión de la costumbre y la tradición jurídica que debiese estar en aquella. Así, en el art.3 del Reglamento del citado Congreso se señalaba como finalidad del mismo: "el estudio y, consecuentemente, proponer las soluciones del caso a la problemática actual de la vida jurídica gallega y en especial de las instituciones propias del Derecho civil especial de Galicia, con ocasión de la revisión decenal de la vigente Compilación". Trece años más tarde. en el mes de junio de 1985, afirmada la identidad gallega con el Estado de las Autonomías, se celebró un II Congreso de Derccho gallego, dirigido, según se indicaba, a la profundización y potenciación del Derecho gallego, tratando de extraer del mismo los principios generales que lo forman, sus fuentes y su causá originadora, para conservarlo y desarrollarlo, así como tambićn para proceder a analizar los cauces por los que debería de circular el Derecho que, en virtud de las competencias conferidas por el Estatuto de Autonomía gallego, se puede hacer en Galicia y para Galicia, sin perder de vista los territorios vecinos y los de habla hispana que se encuentran al otro lado del Océano. Una amplia y documentada referencia del I Congreso de Derccho Gallego, se puede consultar en el Libro del I Congreso de Derecho Gallego, promovido por los llustres Colegios de Abogados de Galicia y la Academia Gallega de Jurisprudencia y Legislación, editado por la Comisión Ejccutiva del I Congreso de Derecho Gallego, 1974. Para el II Congreso de Derecho Gallego, vid. una referencia sucinta del mismo en la Revista jurídica general de Gálicia, Foro Gallego, núm. 182, 1986, p.10 ss. 
Xustiza, Interior e Relacións Laborais, a la que ahora se encuentra adscrita, y, sobre todo, a la nueva realidad social e institucional, con la inclusión de nuevos vocales ${ }^{42}$ que puedan acercar su experiencia y conocimiento contrastados. Dicha Comisión Superior se estructura como el órgano consultivo de la Xunta de Galicia, realizando estudios y emitiendo dictámenes e informes solicitados por la Administración autonómica, por medio del Conselleiro de Xustiza, Interior e Relacións Laborais, entre otras y por lo cue aquí interesa, en materia de "conservación, modificación y desenvolvimiento de las instituciones del derecho civil gallego (art.27.4 del Estatuto de Autonomía para Galicia, en relación con el art.149.1.8 de la Constitución española)".

En el momento en que se redactan estas líneas, la mencionada Comisión Superior se encuentra trabajando en la posible revisión de la Ley ${ }^{43}$.

\section{LA IMPORTANTE FUNCIÓN DESEMPEÑADA POR EL TRIBUNAL SUPERIOR DE JUSTICIA DE GALICIA DESA- RROLLADA A TRAVÉS DE SU ACTIVIDAD JURISPRU- DENCIAL. DOS EJEMPLOS DE DETERMINACIÓN JURIS- PRUDENCIAL DEL DERECHO EN MATERIA DE SERVI- DUMBRES Y SERVENTÍAS.}

La referida falta de actividad legislativa, hasta el momento presente, contrasta, por el contrario, con la actividad que desde la entrada en vigor de la LDCG han venido y vienen desarrollando los órganos jurisdiccionales que actúan en el ámbito de la Comunidad gallega, y, en especial, con la realizada por el Tribunal Superior de Justicia de Galicia (TSJG) ${ }^{44}$ a través de sus sentencias dictadas en casación en materia de Derecho civil gallego.

42 La mencionada Comisión actualmente se encuentra integrada por los siouientes miembros: el Conselleiro de Xustiza, Interior e Relacións Laborais; el Secretario Xeral de la citada Consellería; el Director Xeral de Xustiza c Administración Local; el Director Xeral-xefe de la Asesoría Xurídica xeral de la Xunta de Galicia; un representante del Consello da Cultura Galega, del Consello de la Avogacía de Galicia, del Colegio Oficial de Registradores de la Propiedad y Mercantiles, y del Colegio Notarial de Galicia, respectivamente, elegidos de entre sus miembros; un representante por cada una de las tres Universidades gallegas, que deberán ser Catedráticos de sus respectivas Facultades de Derecho; un representante nombrado por el Tribunal Superior de Justicia de Galicia de entre los miembros de la Sala de lo Civil y Penal del Alto Tribunal; y hasta tres vocales más, designados por el Conselleiro de Xustiza, Interior e Relacións Laborais entre personas de reconocida competencia profesional en la materia; así, como también, finalmente, un representante de la Academia Galega de Xurisprudencia e Lexislación, elegido de entre sus micmbros (este último, añadido en virtud de lo dispuesto en el Decreto 182/1999, de 17 de junio, dictado con posterioridad al referido Decreto 107/1999).

43 Dicha situación de presente nos pone en conexión con el porvenir, en relación al cual se plantean diversas incógnitas importantes, cuyas respuestas son inciertas: ¿cuál será el futuro del Derecho civil galle go?; ¿se va a volver a reabrir el antiguo y apasionado debate, no resuelto por la vigente LDCG, entrc foralismo y autonomismo?; ¿se va a proceder simplemente a retocar la actual LDCG, o se va a afrontar una reforma seria y en profundidad de la misma?. Desde luego, sin lugar a dudas, el alcance y las importantes implicaciones prácticas que, desde un punto de vista jurídico, puede presentar una posible revisión o reforma de la Ley 4/1995, sugieren, a nuestro juicio, la deseable celebración de un debate lo más amplio posible, quizá mediante la realización de un III Congreso de Derecho Gallego, en el que los diversos operadores jurídicos que actúan en el ámbito de esta Comunidad contrasten sus opiniones al respecto.

44 En relación a la consideración de los Tribunales Superiores de Justicia como órganos judiciales que desarrollan su función en las Comunidades Autónomas llevando a cabo una "modulación autonómica de la Administración de justicia", con especial atención al TSJ de Galicia, cfr. RODRIGUEZ ENNES, $O$ Tribunal Superior de Xustiza e a Comunidade Autónoma, en REGAP, núm.11, 1995, p.61 ss. Respecto a las cuestiones relativas al marco constitucional de la organización jurisdiccional en cl Estado autonómico, cl marco estatutario, la competencia de los poderes autonómicos en relación con la "administración de la Administración de Justicia", la organización del TSJ de Galicia y la competencia en los diversos ordenes de los órganos jurisdiccionales radicados en la Comunidad Autónoma Gallega, vid., con referencias bibliográficas, FERNANDEZ SEGADO, O Tribunal Superior de Xustiza de Galicia, en Manual de Dercito Galego, AA.VV, 1996, p.263 ss. 
En el art.2.2 de la LDCG, el legislador gallego alude a la jurisprudencia, junto con los principios generales que informan el derecho gallego, los usos y costumbres, y la doctrina que encarna la tradición jurídica gallega, como elementos de interpretación e integración del Derecho gallego.

Dicha mención conjunta que se realiza en el artículo de los usos y costumbres, y los principios generales que informan el derecho gallego, con la jurisprudencia y la doctrina que encarna la tradición jurídica gallega, ha sido calificada por un sector de la doctrina como "poco afortunada"

La citada norma, con la que el legislador gallego parece querer completar lo preceptuado en el artículo 1 de la Ley ${ }^{4 \hbar}$, plantea en sus términos literales, según se dice, una importante cuestión: al margen de la Ley, la costumbre y los principios generales, ¿existen o no otras fuentes del Derecho civil gallego ${ }^{247}$; o, lo que es lo mismo, ila doctrina que encarna la tradición jurídica gallega $a^{4 \times}$ y la jurisprudencia, tienen también la consideración de fuentes del Derecho civil gallego?.

Esta cuestión trascendental encuentra en los muy pocos autores que hasta el momento se han hecho eco de la misma en la Comunidad gallega -por lo general, sin excesivo detenimiento ${ }^{49}$ - una respuesta negativa.

$\mathrm{Al}$ respecto se ha indicado, por ejemplo, que "la jurisprudencia y la doctrina que encarna la tradición jurídica gallega, deberán configurarse como elementos informadores del sistema, e inclusive (en lo que se refiere a la doctrina jurisprudencial) realizadores de una unificadora interpretación de lo que se tenga por fuentes, pero sin que quepa calificarlos, ambos, propiamente de fuentes formales o constitutivas de dicho sistema", puesto que "ni la jurisprudencia ni la doctrina son, en puridad, fuentes del dere-

45 BELLO JANEIRO, El ejercicio de la competencia en materia civil cit., p. 89. Obsérvese la similitud, con ciertas matizaciones, entre la redacción que el legislador gallego da al art. 2.2 de la LDCG. con la de los arts. 1, párrafo $2^{\circ}$, de la Ley $8 / 1990$, de 28 de junio, de la Compilación del Derecho civil de Balcares - "El derecho civil de Baleares se interpretará e integrará tomando en consideración los principios generales que lo informan, así como las leyes, costumbres, jurisprudencia y doctrina que encarnan la tradición jurídica de las islas"-, y el art.1, párrafo $2^{\circ}$ de la Compilación catalana -"Para interpretar e integrar esta Compilación y las restantes normas se tomarán en consideración las leycs, las costumbres, la jurisprudencia y la doctrina que constituyen la tradición jurídica catalana, de acuerdo con los principios que inspiran el ordenamiento jurídico de Cataluña"-. Cfr. BELLO JANEIRO, op. cit., p.89 ss.; GARCIA RUBIO, Las fuentes del Derecho civil gallego, en Manual de Derecho civil gallego, 1999, p.40.

46 SEOANE IGLESIAS, Unha aproximación ás fontes do Dereito civil de Galicia, en Dercito civil de Galicia (Comentarios á Lei 4/1995 do 24 de Maio), s.f., pero 1996, p.27

47 La cuestión aparece expresamente planteada en los términos transcritos, entre otros, por PENA LOPEZ, Comentarios a los arts. $1^{\circ}$ a $3^{\circ}$ de la $L D C G$ cit., p. 101 ss., y GARCIA RUBIO, Las fuentes del Derecho civil gallego cit., p.39.

48 Expresión ésta que, como indica GARCIA RUBIO, Las fuentes del Derecho civil gallego cit., p.40, es de difícil concreción, y que, según dicha autora, siguiendo el planteamiento formulado por Roca Tríns en relación al Derecho catalán, podría hacer referencia a "todos aquellos autores cuya opinión ha contribuido a formar el Derecho gallego actual". En opinión de PENA LOPEZ, Comentarios a los arts. $1^{\circ}$ a $3^{\circ}$ de la $L D C G$ cit., p110 s., el concepto de "doctrina que encarna la tradición jurídica gallega", habría que referirlo a "la doctrina sentada por los autores al crear -en proyecto- o interpretar normas de Derecho civil gallego, siempre que aquélla tenga la consolidación e institucionalización que supone su naturaleza de tradicional".

49 En nuestra opinión, la circustancia de que el mencionado problema se haya tratado desde un punto de vista eminentemente teórico, y no práctico, ha provocado la adopción de una posición apriorística y dogmática de la que se parte en cuanto a su posible resolución, motivando habitualmente una necesaria falta de atención respecto de los particulares matices que en la actualidad creemos se dan en torno al mismo. Cfr., a modo de ejemplo, la sucinta exposición realizada en la doctrina gallega, entre otros, por SEOANE IGLESIAS, Unha aproximación ás fontes do Dereito civil de Galicia cit., p.28; DIAZ FUENTES, Dereito civil de Galicia cit., p.22; GARCIA RUBIO, Las fuentes del Derecho civil gallego cit., p.39; BELLO JANEIRO, El ejercicio de la competencia en materia civil cit., p.89. También se ocupa del tema, pero con mayor extensión, PENA LOPEZ, Comentarios a los arts. $1^{\circ}$ a $3^{\circ}$ de la $L D C G$ cit., p. 101 ss. 
cho": "la primera de destacada importancia y relevante papel en la práctica forense, de conformidad con los criterios más comunmente aceptados, no es "creadora de normas" y sí, cabalmente, oriendadora o "indicadora de módulos para la interpretación de las normas discutidas y discutibles (STS. 15 julio 1988; Ar.5722)"; la segunda -"tradición jurídica"- "tampoco se ha de considerar fuente formal,...aun cuando sea de obligada referencia a la que toda tarea interpretativa o indagadora ha de aspirar"."in.

No obstante, a pesar de lo señalado, también se ha resaltado que la existencia de un Tribunal Superior de Justicia de Galicia con competencias para conocer de un recurso de casación en materia de Derecho especial de Galicia, tal y como aparece regulado por la Ley 11/1993, de 15 de julio, del Parlamento de Galicia ${ }^{51}$, puede suscitar ciertas dudas por lo que se refiere al posible papel normativo de la doctrina jurisprudencial sentada por aquél Alto órgano jurisdiccional, de forma paralela, según se dice, a como se plantea en el art. 1.6 del Código Civil, respecto a la doctrina jurisprudencial emanada, en este caso, de las sentencias dictadas por el Tribunal Supremo ${ }^{52}$.

En cualquier caso, aun cuando desde un punto de vista meramente formal y teórico la respuesta ofrecida a la incógnita planteada pueda ser negativa, estimamos que, a consecuencia de la referida falta de iniciativa legislativa, la situación que se está pro-

50 SEOANE IGLESIAS, Unha aproximación ás fontes do Dereito civil de Galicia cit., p.28. Cfi. en sentido similar, DIAZ FUENTES, Dereito civil de Galicia cit. p.22: PENA LOPEZ, Conentario a los arts. $1^{\circ}$ a $3^{\circ}$ de la LDCG cit., p. 101 ss.; BELLO JANEIRO, El ejercicio de la competencia en materia civil cit., p.89; GARCIA RUBIO, Las fientes del Derecho civil gallego cit., p.39.

51 En relación a la necesidad de proceder a regular el recurso de casación ante el TSJ de Galicia -á consecuencia, según sostenía un sector de la doctrina gallega, de las especificidades concurrentes en el Derecho civil de Galicia- a través de la correspondiente norma autonómica, que con posterioridad se concretaría en la citada Ley $11 / 1993$-siendo recurrida, a diferencia de la LDCG, por el Gobierno Central bajo alegación de inconstitucionalidad-, vid. GARCIA CARIDAD, Encontros sobor da casación no Tribunal Superior de Xustiza de Galicia (Encuentros sobre la casación en el Tribunal Superior de Justicia de Galicia), 1990. Más recientemente, respecto al complicado tema relativo a los conflictos de competencias entre el Estado y las Comunidades Autónomas en el ámbito procesal, vid., BUSTO LAGO, Competencia legislativa de las Comunidades Autónomas sobre las "necesarias especialidades" procesales que se deriven do su Derecho substantivo propio (Comentario a la STC 127/1999, de I de julio), en Derecho Privado y Constitución, núm.13, 1999, p.81 ss.

52 Cfr. PENA LOPEZ, Comentarios a los arts. $7^{\circ}$ a $3^{\circ}$ de la LDCG cit., p.101 ss.; GARCIA RUBIO, Las fuentes del Derecho civil gallego cit., p.39

Como ha señalado LOPEZ GUERRA, La legitinidad democrática del juez, en Cuadernos do Derecho Público, núm. 1, 1997, p.54 ss., "La discusión sobre si la jurisprudencia (i.e. la jurisprudencia de Tribunal Supremo, en fórmula redundante) es o no fuente del Derecho es un lugar clásico en la litcratura jurídica. Pero puede que sea una discusión inútil si se ciñe al deber ser, puesto que lo relevante, a los efectos de la justificación del poder judicial, es si de hecho los Tribunales crean Derecho objetivo (normas generales) o no, y hasta qué punto ello es (o puede hacerse) compatible con el principio democrático. Desde una perspectiva fáctica, parece difícil negar que la jurisprudencia establece pautas de comportamiento generales, que vinculan a los jueces y tribunales. Las distintas reformas de la Ley de Enjuiciamiento Civil han ido, cn forma paulatina pero continua, en una dirección fortalecedora del valor de la jurisprudencia, incluso convirtiéndola en criterio para la inadmisión de la demanda de casación (art.1710.1.3 LEC) -en este scntido, vid., añadimos nosotros, el art.477 de la nueva LEC-. No sería correcto, de todas formas estimar que la creación de jurisprudencia es tarea exclusiva del Tribunal Supremo: más bien debería hablarse de una tarea colectiva de todos los tribunales, en que al Supremo le correspondería la última palabra, al pronunciarse sobre interpretaciones del ordenamiento propuestas por tribunales inferiores, confrmándolas o denegándolas. El orígen de la jurisprudencia vendría, por así decirlo, desde abajo: su fuera vinculante (en virtud, por ejemplo, del art.1692.4 LEC) vendría desde arriba, en cuanto doctrina legal contenida en la jurisprudencia del Tribunal Supremo. Habría así una creación judicial del Derecho, (al menos por vía interpretativa en Ia teoría "clásica"), en cuanto pauta general de conducta. El Derecho a aplicar ya no sería (o, más concretamene, ya no scría sólo) el Derecho cla borado por los órganos de representación popular, directa o indirecta, sino que tendría también un componente judicial... No es fácil hoy, a la vista de la realidad, negar que, por la vía de la interpretación o complementáción de la ley, o por la vía de la interpretación o aplicación directa de la Constitución, se está creando un auténtico "Derecho Judicial" en los países europeo-occidentales, y ciertamente en España...". 
duciendo en la práctica jurídica gallega presenta en gran medida unas características peculiares que, en cierto sentido, contribuyen, cuanto menos a matizar la respuesta precedentemente indicada.

Frente al momento temporal en que por obra del movimiento codificador se produjo, a lo largo del siglo XIX, la identificación del derecho con la normatividad establecida por el Estado a través de la legislación, rompiendo con la concepción jurisprudencial que el ius commune había introducido en la cultura jurídica europea al asignar a la actividad jurisprudencial una función meramente declarativa, negándole todo valor creativo en el plano de la normatividad, actualmente se puede constatar como dato cierto el hecho de que la realidad normativa tiende a presentarse en los actuales sistemas jurídicos continentales en la forma que reviste la interpretación de la legalidad -ahora no necesariamente identificada con los cuerpos normativos codificados, como demuestra la vertiginosa dinámica a que se encuentra sometida la realidad social moderna-, tanto a través de las decisiones judiciales como de las formulaciones realizadas al respecto por la doctrina científica ${ }^{53}$.

Por lo que se refiere a los diversos órganos jurisdiccionales, la labor jurisprudencial, desarrollada siempre y en principio a través de la interpretación de la normatividad establecida legislativamente, no se limita hoy en día a la mera aplicación mecánica de la normatividad contenida en los textos legislativos, sino que, en determinadas ocasiones, también procede a determinar y a desarrollar el ordenamiento jurídico de que se trate, sobre todo, cuando el propio ordenamiento, como a veces suele ser habitual, no ofrezca soluciones legislativas a problemas cuyo planteamiento resulte ciertamente previsible, o bien, cuando, sin darse esa posibilidad de previsión, tales problemas aparezcan motivados por nuevas necesidades sociales que resulte necesario solucionar y que, precisamente a consecuencia de su imprevisibilidad, no hayan sido debidamente contemplados en la norma por el legislador, asumiendo de esta forma una función que sustancialmente podría ser calificable como de creación ${ }^{54}$, la cual, como ya se ha indicado, tradicionalmente viene siendo atribuida con carácter exclusivo al propio legislador, siempre y cuando se adopte una postura restrictiva en materia competencial.

53 PARICIO-FERNANDEZ BARREIRO, Historia del Derecho Romano y su recepción europea, $2^{x} \mathrm{ed}$. revisada, 1997, p.285ss.

La influencia de la doctrina en todas aquellas situaciones en las que un ordenamiento jurídico no es claro o presenta lagunas, resulta evidente. Esta circustancia se puede constatar perfectamente, por ejemplo, en materia de servidumbres, a través de la lectura de las resoluciones casacionales dictadas por el TSJ de Galicia 15/98 y 16/98, a las que nos referiremos infra: obsérvese en las mismas la justificación que cl Alto Tribunal realiza de la frase contenida en el inciso final del ar1.25 LDCG, y compárese con determinados planteamientos doctrinales formulados con anterioridad por un sector de la doctrina gallega. En relación a esta cuestión, remitimos a nuestro estudio titulado Reflexiones críticas sobre el reconociniento de la usucapión como forma de constitución de las servidumbres de paso en la vigente Ley $4 / 1995$ de 24 de mayo, de Dereito civil de Galicia, en La Ley(Galicia), suplemento al núm. 4997, 22 de febrero de 2000, p.8 ss., y bibliografía allí citada.

54 Así, en este contexto, la jurisprudencia vuelve a cobrar, aun inconscientemente, la importancia que, en un tiempo pasado y lejano, tuvo en la cultura jurídica europea, contribuyendo por aquel cntonces a la creación y desarrollo de un Derecho Común en la Edad Media, y, a partir de éste, a la del derecho propio de las distintas entidades nacionales que se formaron posteriormente. Cfr. FERNANDEZ BARREIRO, Derecho Común y Derechos nacionales en la tradición juridica europea (Discurso leido el día 9 de noviembre de 1990 en la solemne sesión de ingreso en la Academia Gallega de Jurisprudencia y Legislación), 1991; ID, La tradición romanística en la cultura jurídica europea, 1992. Para esta última obra vid. nuestra recensión a la misma, publicada en IVRA (Riv. internazionale di Diritto Romano e Antico), vol.43, 1992 (pubbl. 1995), p.169 ss. Cfr, asimismo, BELLOMO, La Europa del Derecho Común, 1996. Tal monografía, tuvimos ocasión de recensionarla en Anuario da Facultade de Dercito da Universidade da Coruña, vol.2, 1998, p.799 ss. 
Estas consideraciones formuladas con carácter general resultan plenamente aplicables, con particular intensidad, al ámbito jurídico-civil gallego, donde la labor desarrollada por la jurisprudencia cobra especial relevancia ${ }^{55}$.

Así como en relación al pasado se suele destacar, por ejemplo, la importante labor jurisprudencial desarrollada por la Real Audiencia de Galicia, procediendo, según se dice, a realizar la "oficialización" o "generalización oficial de las antiguas figuras gallegas de orígen consuetudinario", "acuñando precedentes judiciales" cio, en la actualidad el Tribunal Superior de Justicia de Galicia también se encuentra desarrollando una importante función en el ámbito del Derecho civil gallego, como se puede apreciar perfectamente a través de la lectura de sus diversas resoluciones casacionales dictadas en la citada materia.

Con la finalidad de poder constatar dicha afirmación hemos elegido, entre otros, dos posibles ejemplos significativos de determinación jurisprudencial del derecho -en este caso, gallego-, ambos en materia de derechos reales ${ }^{57}$, referidos respectivamente a dos instituciones particularmente importantes y conflictivas, que aparecen reguladas por la vigente LDCG: uno relativo a las servidumbres de paso, y otro relativo a las serventías.

El primero de los ejemplos atañe a la resolución del grave problema -que hemos tenido ocasión de examinar más detenidamente en diversos escritos ${ }^{58}$ - planteado respecto a la determinación de la posible aplicación con carácter retroactivo o irretroactivo de lo dispuesto en el art.25 de la LDCG en materia de constitución de servidumbres de paso por usucapión.

55 Llegando en algunas ocasiones a inadmitir el recurso correspondiente interpuesto por la parte de que se trate, a consecuencia de la introducción por aquella de una serie de cuestiones jurídicas nuevas y distintas de las planteadas en las instancias jurisdiccionales anteriores, pero entrando en el fondo del asunto, aun cuando lo sea, según se indica, a efectos meramente clarificadores, como por ejemplo ocurre en la sentencia dictada por la Sala de lo Civil y Penal con fecha de 24 de abril de 1999. Vid., al respecto, EN.JO MALLOU, Comentario á sentencia do 24 de abril de 1999 do Tribunal Superior de Xustiza de Galicia (Sala do Civil e Penal), en Revista Xurídica Galega, núm.23, 1999, p.263 ss.

56 DIAZ FUENTES, Dereito civil de Galicia cit., p.12. En sentido similar y también dentro del ámbito jurisdiccional, GIBERT puso de manifiesto en El Derecho civil de Galicia cit., p.540, la posible existencia, registrada a partir de 1856 a través de la Revista de ámbito regional Boletín Judicial de Galicia, de una mayor complejidad de la realidad jurídica gallega que la limitada a las dos instituciones consuetudinarias tradicionales recogidas en su Memoria de 1880 por López Lago: el foro y la compañía familiar gallega.

57 Respecto a la regulación que se realiza en la LDCG de la materia señalada, remitimos con carácter general a nuestros trabajos Anotaciones en torno al régimen jurídico de las servidumbres y serventías en la vigente Ley de Derecho civil de Galicia, en Foro Galego, núm.189, 1999, p.57 ss., y La regulación de las servidumbres y serventías en la Ley 4/1995 de Derecho civil gallego: un análisis crítico y comparativo con la Legislación civil de otras Comunidades Autónomas, en Revista Xurídica Galega, núm. 14, 1996, p.37 ss., y bibliografía citada en los mismos. Cfr., además, la rigurosa y completa monografía de REBOLLEDO VARELA, Los derechos reales en la Ley 4/1995, de 24 de mayo, de Derecho civil de Galicia cit.

58 Anotaciones en torno al régimen jurídico de las servidumbres y serventías en la vigente Ley de Derecho civil de Galicia cit., p.59 ss.; La regulación de las servidumbres y serventías en la Ley $4 / 1995$ de Derecho civil gallego: un análisis crítico y comparativo con la Legislación civil de otras Comunidades Autónomas cit., p.45 ss.; Inhibición lexislativa e determinación xurisprudencial do dereito: iaplicación retroactiva ou irretroactiva do art.25 da LDCG en materia de constitución de servidume de paso por usucapión? (Comentario ás SS.TSX Galicia 15/98 e 16/98 do 24 de Setembro de 1998), en REGAP, núm.20, 1998, p.241 ss.; Inhibición legislativa y determinación jurisprudencial del derecho: ¿aplicación retroactiva o irretroactiva del artículo 25 de la Ley de Dereito civil de Galicia en materia de constitución de servidumbres de paso por usucapión? (Comentario a las sentencias del Tribunal Superior de Justicia de Galicia 15/1998 y 16/1998, de 24 de septiembre), en La Ley(Galicia), suplemento al núm.4777, 19 de abril de 1999, p. 1 ss.; Apostillas a la declaración jurisprudencial de irretroactividad en materia de constitución de las servidumbres de paso en Galicia (Comentario a la STSX Galicia n²/99, de 2 de marzo de 1999), cn Anuario da Facultade de Dereito da Universidade da Coruña, núm.3, 1999, p.691 ss.; Reflexiones críticas sobre el reconocimiento de la usucapión como forma de constitución de las servidumbre de paso en la vigente Ley $4 / 1995$ de 24 de mayo, de Dereito civil de Galicia cit., p.8 ss. 
Dicho problema de derecho intertemporal, ciertamente previsible en una Comunidad como la gallega, en la que desde siempre todas las cuestiones relativas a la agricultura han presentado un carácter primordial, despertando la sensibilidad popular, y que, también, desgraciadamente, en bastantes ocasiones, como demuestran los acontecimientos históricos, ha desatado pasiones incontroladas en la vida cotidiana, no fue tomado en consideración por el legislador gallego al proceder a la redacción de la vigente Ley de Derecho civil de Galicia.

El legislador gallego, dando un paso adelante y con carácter totalmente novedo$\mathrm{so}^{59}$, se limitó entonces a reconocer en el segundo inciso del art.25 del mencionado cuerpo normativo la posibilidad de que los particulares pudiesen adquirir por prescripción las servidumbres de paso, junto a otros posibles modos o formas de constitución -ley, "dedicación del dueño del predio sirviente", negocio jurídico bilateral-, cumpliendo unos requisitos determinados -posesión pública, pacífica e ininterrumpida durante el plazo de veinte años-, dando así respuesta a una supuesta necesidad social sentida desde antiguo en el ámbito agrario gallego, intentando poner fin a la conflictividad causada por la proliferación de servidumbres de paso y la falta de los correspondientes títulos constitutivos.

Sin embargo, a tal previsión legislativa, entendida en el sentido de reconocer claramente la usucapión como posible forma de constitución de las servidumbres de paso, no acompañó la resolución de un problema directamente conectado con el reconocimiento de la institución, cuyo planteamiento necesariamente se produciría en el futuro, como intuyó y puso de manifiesto la doctrina, y confirmó el desarrollo posterior de los acontecimientos: el relativo a la determinación de la posibilidad de aplicar la novedosa forma de constitución reconocida en el ámbito gallego (prescripción adquisitiva) con carácter irretroactivo o retroactivo, es decir, disponiendo que únicamente aprovecharían a los efectos de la adquisición de las servidumbres de paso por prescripción las situaciones posesorias -que, lógicamente, cumpliesen los demás requisitos establecidos por la Ley- a partir de la entrada en vigor del cuerpo normativo, o bien, que también podrían ser alegadas y reconocidas con plenos efectos aquellas otras situaciones posesorias que, cumpliendo los requisitos señalados en el art.25 de la LDCG, se hubiesen venido ejercitando con anterioridad en el tiempo a la mencionada entrada en vigor de la propia Ley.

De esta forma, el legislador gallego perdió incomprensiblemente la oportunidad histórica de actuar adelantándose a los acontecimientos, ofreciendo legislativamente la solución a la cuestión indicada en cualquiera de los dos sentidos apuntados -como por el contrario sí se hizo en otras Compilaciones y Leyes civiles de diversas Comunidades Autónomas-, evitando, como sucedió, su planteamiento posterior.

Por lo demás, la resolución legislativa del entonces en ciernes problema de la intertemporalidad en materia de prescripción adquisitiva de las servidumbres de paso se podría haber efectuado, como avanzábamos en otros escritos ${ }^{601}$, sin mayores dificultades, por la vía que parecía más simple, lógica y segura: la introducción en la Ley de una disposición transitoria específica -motivada, tanto por la especificidad y dificultad de la cuestión planteada, cuya problemática en el ámbito del ordenamiento común era sobradamente conocida, como por la novedad que suponía dicho reconocimiento de la prescripción adquisitiva en relación a las servidumbres de paso en el ordenamiento gallego,

59 Así creemos haberlo demostrado en Reflexiones críticas sobre el reconocimiento de la usucapión como forma de constitución de las servidumbres de paso en la vigente Ley $4 / 1995$ de 24 de mayo, de Dereito civil de Galicia cit., p.1 ss.

60 Vid., por ejemplo, Inhibición legislativa y determinación jurisprudencial del derecho: ¿aplicación retroactiva o irretroactiva del art.25 de la Ley de Dereito civil de Galicia en materia de constitución de ser vidumbres de paso por usucapión?, p.2. 
en el que hasta entonces había sido ignorada- en la que se previese la retroctividad o irretroactividad.

Lo cierto es que, por los motivos que fuesen, el legislador gallego, no lo hizo, y únicamente se limitó a introducir en la Ley una críptica Disposición transitoria $4^{\mathrm{a}}$ a modo de "cajón de sastre", con la loable finalidad de poder resolver -sin excesivas garantías- todos aquellos problemas de derecho intertemporal que, como el señalado previsible en cuanto a su planteamiento y dotado de particular especificidad por lo que se refería a su resolución, lo que debería haber motivado una atención especial por parte del citado legislador- no se encontrasen solucionados en ninguna de las otras tres disposiciones transitorias anteriores, referidas -como la que ahora nos ocupa- a cuestiones concretas y de previsible conflictividad, relativas a los contratos de arrendamientos rústicos celebrados con anterioridad a la entrada en vigor de la Ley, a los arrendamientos rústicos históricos y a las aparcerías.

La que, no sin cierto rubor y con las reservas oportunas, cabría calificar como "negligencia legislativa", supuso la necesaria remisión y resolución del complicado problema a los órganos jurisdiccionales, provocándose un vaticinado incremento de la litigiosidad.

Paradójicamente, aun cuando el problema en cuestión se presentase en puridad como un claro y previsible problema de política legislativa, su resolución se llevó a cabo, ante la inhibición del legislador, por la vía jurisdiccional ${ }^{61}$.

En este sentido, la Sala de lo Civil y Penal del Tribunal Superior de Justicia de Galicia, dictó en casación dos históricas sentencias con fecha de 24 de septiembre de 1998 -recursos 15/98 y 16/98-, en las que, por primera vez, el Alto Tribunal analizaba y resolvía -a través de un iter interpretativo que calificábamos como enrevesado y laberíntico-, con especiales difícultades, el dilema planteado y no resuelto previamente, como hubiese sido lo deseable, por el legislador gallego, pronunciándose -a nuestro juicio, acertadamente- por la aplicación irretroactiva de lo dispuesto en el art.25 de la LDCG en materia de constitución de servidumbres de paso por prescripción adquisitiva ${ }^{62}$. Con posterioridad a dichas resoluciones casacionales, la misma Sala volvería a pronunciarse de nuevo sobre dicha cuestión en otra sentencia -la tercera cronológicamente en el tiempo-, dictada con fecha de 2 de marzo de 1999 -recurso 4/99-, en la que procedió a clarificar definitvamente el problema, resolviendo las posibles dudas que racionalmente sugería la lectura de las dos resoluciones dictadas anteriormente en la materia $a^{63}$, cerrándose de esta forma, a través de la interpretación jurisprudencial, un período de incertezas y dudas que había sido provocado por una inexcusable falta de previsión legislativa ${ }^{64}$.

61 Respecto al la cada vez más acusada tendencia por parte del legislador que se concreta cn deferir determinadas decisiones propiamente legislativas, confiando su solución a los órganos jurisdiccionales, cfr., reciente y críticamente, desde un punto de vista constitucional, ROURA GOMEZ, El conflicto en defensa de la Autonomía local, en Rev. Vasca de Administración Pública, núm.55, 1999, p.248 ss., y bibliografía allí cit.

62 Para un estudio más detenido de las mencionadas resoluciones, remitimos a nuestros artículos Inhibición lexislativa e determinación xurisprudencial do dereito: ¿aplicación retroactiva ou irretroactiva do art.25 da LDCG en materia de constitución de servidume de paso por usucapión? cit., p.241 ss; Inhibición legislativa y determinación jurisprudencial del derecho: japlicación retrocictiva o irretroactiva del artículo 25 de la Ley de Dereito civil de Galicia en materia de constitución de servidunbres de paso por usucapión? cit., p.1 ss.

63 Para un análisis de los extremos contenidos en esta importante sentencia dictada por el TSI de Galicia, en comparación con las dos resoluciones casacionales anteriores -recursos 15/98 y $16 / 98$ - del mismo órgano jurisdiccional, remitimos a nuestro comentario Apostillas a la declaración jurisprudencial de irretroactividad en materia de constitución por uscapión de las servidumbres de paso e Galicia cit., p.691 ss.

64 En relación a los efectos prácticos derivados de la declaración jurisprudencial de irretroactividad de la usucapión en materia de constitución de servidumbres de paso -aplicación irretroactiva de lo dispuesto en el art.25 LDCG- y la paradójica reacción operada al respecto en la actualidad por un sector de la doctrina 
El segundo ejemplo de determinación jurisprudencial del derecho, al que ahora nos referiremos, permite apreciar una actuación por parte del Tribunal Superior de Justicia de Galicia que, en nuestra opinión, quizá pudiera llegar a calificarse como sustancialmente creativa. La lectura de las consideraciones que, en un plano no ya meramente procesal sino estrictamente sustantivo, se contienen en la sentencia dictada por el Alto Tribunal, con fecha de 24 de junio de 1997, cn este caso, respecto a la caracterización de la figura jurídica de serventía, en referencia a su forma de constitución, parecen confirmar esta idea.

Como tuvimos ocasión de indicar en otro escrito, en el que nos ocupábamos de comentar la referida resolución casacional ${ }^{6,5}$, en la misma, el Magistrado Ponente, partiendo del dato concreto que concurría en el supuesto objeto de la litis -relativo a la cesión efectuada en el año 1959 por los padres de la actora (apelante y recurrente) del terreno que en su momento compraron y por el que desde la mencionada fecha venía discurriendo el camino serventío actual en su tramo final, camino cuya cesión se produjo a cambio de la incorporación del camino serventío antiguo a uno de los predios pertenecientes a los padres de la recurrente, consumada con el consentimiento de los cotitulares y por ello usuarios de aquél camino serventío, lo que, a su vez, produjo la consiguiente modificación o alteración del mencionado lugar de paso- encontraba un apoyo que, en su opinión, corroboraba la tesis avanzada por la doctrina jurisprudencial y científica gallega -implícitamente recogida en los arts.30 y 31 de la LDCG-, según la cual, el orígen de la serventía podría hallarse en el "agra" o "vilar", pero sin que su vinculación a las mismas -y en ello estribaría la importancia del razonamiento- lo fuese con carácter exclusivo, puesto que tal institución también se daría en todos aquellos casos en los que -como ocurría en el supuesto judicial concreto planteado- los titulares de las "leiras" contiguas se pusiesen de acuerdo cediendo, casi siempre por su cabecera, terreno o una franja de su "leira" para servicio de todos los predios, con la finalidad de poder tener un acceso más cómodo que les permitiese, de esta forma, alcanzar un camino público.

La precisión efectuada por la Sala supone la confïrmación jurisprudencial del reconocimiento de la condición de serventía no sólo en aquellos supuestos fácticos en los que el camino discurra por fincas de propietarios que integren un "agra" o "vilar" -a los que parece referirse fundamentalmente la $\mathrm{LDCG}^{-}$, sino también en aquellos otros en los que los predios, evidentemente contiguos, no se encuentren enclavados en dichas distribuciones territoriales o geográficas, exigiéndose únicamente en este último caso, como se señala en la sentencia comentada, el requisito de que se produzca una cesión, lógicamente voluntaria y consensuada", de una parte de terreno de cada "leira" o finca particular de los constituyentes, estableciéndose de esta forma -de mutuo acuerdo y mediante las correspondientes cesiones de parte del terreno realizadas al efecto- el camino serventío.

gallega, formulando una serie de propuestas enmarcables en el recurso a Ia vía jurisdiccional, con la finalidad, según manifiestan, de poder encontrar soluciones que "ante el amplio período de derecho transitorio impuesto por la Ley 4/1995" permitan "solventar el problema ancestral de la servidumbre de paso en Galicia" y que, de forma "relativa y temporal", faciliten para cstos primeros veinte años un mayor número de "posibilidades en favor del reconocimiento de las servidumbres", vid. nuestras Reflexiones criticas sobre el reconocimiento de la usucapión como forma de constitución de las servidumbres de paso en la virente. Ley 4/I995 de 24 d mayo, de Dereito civil de Galicia cit., p. 11 ss. Para una sucinta crítica a los citados planteamientos, remitimos a la op. cit., p.13.

65 Vid., Precisiones históricas y jurisprudenciales en materia de serventáas: comentario a la STS.I Galicia de 24 de junio de 1997, en Revista Xurídica Galega, núm.16, 1997, p.303 ss.

66 La voluntad consensuada de los particulares constituyentes de líl serventía resultaría decisiva tanto en cuanto a la necesaria y concretá detcrminación del lugar material exacto sobre el que se va a establecer cl camino al que se atribuye ía consideración de serventío, como en todos aquéllos supuestos cn los que, una vez establecida la serventía, cualquiera de los cotitulares pretendiese realizar alguna modificación o alteración del espacio físico por el que dicho camino discurriese -por ejemplo, como ocurrc en el supucsto objeto de litigio que nos ocupa, permutando una cierta zona de terreno de ese terreno común destinado al paso, 
Por consiguiente, desde un punto de vista meramente práctico, todo lo indicado implica el reconocimiento -realizado no ya normativamente, sino jurisprudencialmente- de una doble posibilidad a favor de los propietarios que deseasen establecer voluntariamente determinados servicios de paso a favor de sus predios, al poder optar aquéllos para conseguir tal finalidad, indistinta y alternativamente por cualquiera de las dos vías siguientes: o bien por constituir una servidumbre de paso, o bien por establecer una serventía, con independencia de que los citados predios se encontrasen encuadrados en un "agro", debiendo en este último caso, como se ha señalado, ceder de forma voluntaria y consensuada cada uno de los propietarios una parte de terreno de su finca particular para establecer el camino serventío.

Los dos ejemplos sucintamente expuestos en estas breves notas se presentan como posibles manifestaciones de un fenómeno que, en nuestra opinión, se está produciendo en la realidad jurídica gallega actual ${ }^{67}$, cuyo particular interés y especiales implicaciones, entre otras, en la esfera relativa al ámbito de la configuración y desarrollo del derecho, resultan evidentes; un fenómeno que, a nuestro juicio, permite calificar al concreto momento histórico-jurídico en que nos encontramos como apasionante. A través del presente trabajo simplemente nos hemos limitado a poner de manifiesto dicha circustancia, sin más pretensión que la de plantear el inicio del que podría ser un interesante y fecundo debate jurídico.

que se pretendiese adquirir con caráeter particular, por otra zona de terreno de propiedad exclusiva, que, en caso de consumarse el negocio, adquiriría tras las cesiones recíprocas correspondientes la condición de lugar destinado al paso común-, que implicase una variación de su trazado originario; lógicamente, tal modificación o alteración sería posible en la medida en que todos los cotitulares de la serventía estuviesen de común acuerdo. Una vez producida esa modificación o alteración consensuada del camino serventío, los cotitulares del mismo deberín respetar el nuevo trazado establecido de común acuerdo. Vid. Precisiones históricas y jurisprudenciales en materia de serventías cit., p.306.

67 Con la expresión "realidad jurídica gallega" pretendemos referirnos a la amplia y rica problemática que, dentro del ámbito del Derecho, se ha planteado en la Comunidad gallega a partir y a consecuencia de la promulgación de la Ley 4/1995 de Dereito civil de Galicia, en la que, como es sabido y ya se ha indicado, se establece el marco normativo referencial del ordenamiento jurídico-civil gallego, a cuyo desarrollo se está procediendo, y respecto del que aquélla actúa como punto de referencia fundamental. 